\title{
Analysis of the variability of the North Atlantic eddy-driven jet stream in CMIP5
}

\author{
Waheed Iqbal ${ }^{1}$ (i) $\cdot$ Wai-Nang Leung ${ }^{2} \cdot$ Abdel Hannachi $^{1}$
}

Received: 14 March 2017 / Accepted: 14 September 2017 / Published online: 22 September 2017

(C) The Author(s) 2017. This article is an open access publication

\begin{abstract}
The North Atlantic eddy-driven jet is a dominant feature of extratropical climate and its variability is associated with the large-scale changes in the surface climate of midlatitudes. Variability of this jet is analysed in a set of General Circulation Models (GCMs) from the Coupled Model Inter-comparison Project phase-5 (CMIP5) over the North Atlantic region. The CMIP5 simulations for the 20th century climate (Historical) are compared with the ERA40 reanalysis data. The jet latitude index, wind speed and jet persistence are analysed in order to evaluate 11 CMIP5 GCMs and to compare them with those from CMIP3 integrations. The phase of mean seasonal cycle of jet latitude and wind speed from historical runs of CMIP5 GCMs are comparable to ERA40. The wind speed mean seasonal cycle by CMIP5 GCMs is overestimated in winter months. A positive (negative) jet latitude anomaly in historical simulations relative to ERA40 is observed in summer (winter). The ensemble mean of jet latitude biases in historical simulations of CMIP3 and CMIP5 with respect to ERA40 are $-2.43^{\circ}$ and $-1.79^{\circ}$ respectively. Thus indicating improvements in CMIP5 in comparison to the CMIP3 GCMs. The comparison of historical and future simulations of CMIP5 under RCP4.5 and RCP8.5 for the period 2076-2099, shows positive anomalies in the jet latitude implying a poleward shifted jet. The results from the analysed models offer no
\end{abstract}

Electronic supplementary material The online version of this article (doi:10.1007/s00382-017-3917-1) contains supplementary material, which is available to authorized users.

Waheed Iqbal

waheed.iqbal@misu.su.se

1 Department of Meteorology, Stockholm University, 10691 Stockholm, Sweden

2 ClusterTech Limited, Hong Kong, Hong Kong specific improvements in simulating the trimodality of the eddy-driven jet.

Keywords North Atlantic jet - CMIP5 - evaluation - Jet variability

\section{Introduction}

The two main jet streams affecting the midlatitudes and extratropics are the subtropical and the eddy-driven jets. The former is formed as a result of angular momentum transport by the thermally direct Hadley cell (Held and Hou 1980) whereas the latter one is caused by eddy momentum flux convergence resulting from baroclinic waves (Hoskins et al. 1983; Panetta and Held 1988). The current study is aimed at exploring the variability in the North Atlantic eddy-driven jet. The variability in the position of this jet has direct consequences on the synoptic conditions over the extratropics. Furthermore, the predictability of the synoptic systems over the North Atlantic is associated with the preferred states and transitions in these preferred states of the eddy-driven jet (Franzke and Woollings 2011; Hannachi et al. 2012).

The World Climate Research Program's (WCRP) Coupled Model Inter-comparison Project (CMIP) integrations provide an invaluable tool for the wider climate community to analyse present and future climate variability on a wide range of scales and compare model performance (e.g. Wang et al. 2014; Seiler and Zwiers 2015; Su et al. 2013; Barnes and Polvani 2015; Furtado et al. 2015). The CMIP5 GCMs have been used to study the jet streams in both the hemispheres (e.g. Warner et al. 2015; Merz et al. 2015). Ma et al. (2015) used 20 GCMs to study East Asian Subtropical Jet stream and its meridional location. A strong correlation between the speed of the eddy-driven jet and the width of 
the Hadley cell is found to exist in the Southern Hemisphere in CMIP5 GCMs (Ceppi and Hartmann 2013). The CMIP5 models show negative bias in the blocking frequency over North Atlantic as compared to reanalysis data (Hoffman and Zhou 2015; Anstey et al. 2013). This negative bias in blocking frequency is sufficiently reduced for high resolution GCMs (Anstey et al. 2013).

Hannachi et al. (2013) (HA13 hereafter) evaluated the performance of CMIP3 models in simulating the North Atlantic eddy-driven jet stream variability. They analysed the jet latitude index (Woollings et al. 2010) from CMIP3 GCMs in historical, pre-industrial control and future climate scenarios. Results from HA13 suggest that the CMIP3 models perform well for the jet seasonality. However, the trimodal structure of the jet is not reproduced by most of the models. This short paper is meant to complement the study of HA13 and explore improvements in the same models used for CMIP5 integrations. We have selected all those available models which were used by HA13. In addition to the quantification of the ability of the models, we present the changes in the strength of the North Atlantic jet under the Representative Concentration Pathways (RCP4.5 and RCP8.5). The data and methodology are discussed in Sects. 2, 3 discusses the results from ERA40 and CMIP5 GCMs for historical simulations, and future climate projections; and comparison of CMIP3 and CMIP5 GCMs with a discussion in the following section. A summary and conclusions are presented in Sect. 5.

\section{Data and methodology}

The two important parameters which have been used to explore the jet variability are the jet latitude index and wind speed. The jet latitude index and wind speed are defined as in Woollings et al. (2010); see also HA13. Briefly, the jet latitude index calculations include: (1) daily zonal mean zonal wind over North Atlantic sector $\left(0-60^{\circ} \mathrm{W}, 15-75^{\circ} \mathrm{N}\right)$ vertically averaged over the pressure levels ( 850 and 700 $\mathrm{hPa}$ ), (2) a 10-day low pass filter, and (3) from this filtered average the maximum is the wind speed of the jet and the latitude at which this maximum occurs is the jet latitude. The ERA40 reanalysis daily data (Dee et al. 2005) for zonal wind for the period 1957-2002 is also used to calculate the daily jet latitude. The analysis is performed for the winter (December-March: DJFM) season mainly, however, mean seasonal cycles are also analysed. The term 'jet shift' is referred to the deviation of the jet latitude from a reference state (ERA40 or Historical). Such a deviation being positive will mean poleward shift and a negative deviation will correspond to an equatorward shift of the jet.

The data used in this paper consist of the daily jet latitude index and wind speed derived from the CMIP5 GCMs simulations. HA13 used 13 CMIP3 GCMs from which two models (BCCR-BCM2.0 and ECHO-G; see their Table 1) are not part of the CMIP5 integrations. Therefore 11 GCMs from nine centres have been selected for the analysis; the list of these models along with their horizontal resolutions and origins is presented in Table 1. The model simulations are selected for (1) 20th century: Historical runs for the period 1980-2004, (2) Pre-industrial Control: piControl, (3) Future: RCPs (RCP4.5 and RCP8.5) for the period 2076-2099. A maximum of 25 year time period is chosen to analyse each scenario, however, for two GCMs (INM-CM4 and MRICGCM3) the number of an available time period in piControl simulations was 20 years. The RCPs are the emission scenarios, corresponding to the total radiative forcing due to anthropogenic emissions in future. Specifically, RCP4.5 and RCP8.5 respectively correspond to a stabilized radiation forcing pathway of 4.5 and $8.5 \mathrm{~W} / \mathrm{m}^{2}$ by the end of 2100 (Meinshausen et al. 2011).

The daily jet latitude climatology is calculated by averaging over all years within the selected period. The smoothed seasonal cycle is obtained by filtering jet latitude climatology with Fourier Transforms, followed by retaining only the mean and the lowest two frequencies (Woollings et al. 2010, HA13). The jet latitude anomalies correspond to the differences of model values from the ERA40 jet latitude climatology. The kernel density estimation (Silverman 1981) is used to compute the probability distribution function (PDF) in the jet latitude time series. The standard smoothing parameter $h=1.06 \sigma n^{-1 / 5}$ has been applied, with $\sigma$ and $n$ representing the standard deviation and the sample size of the time series respectively. Third and fourth standardized moments, i.e., skewness and kurtosis of the jet latitude are also analysed for asymmetry and flatness of the PDF. The jet

Table 1 CMIP5 climate models used in this analysis

\begin{tabular}{llll}
\hline Sr. no. & Model & Institution & Resolution \\
\hline 1 & CanESM2 & CCMA & $2.8^{\circ} \times 2.9^{\circ}$ \\
2 & CNRM-CM5 & CNRM-CERFACS & $1.40^{\circ} \times 1.40^{\circ}$ \\
3 & CSIRO-MK3.6-0 & CSIRO-QCCCE & $1.90^{\circ} \times 1.90^{\circ}$ \\
4 & GFDL-ESM-2G & NOAA GFDL & $2.50^{\circ} \times 2.00^{\circ}$ \\
5 & GFDL-ESM-2M & NOAA GFDL & $2.50^{\circ} \times 2.00^{\circ}$ \\
6 & GISS-E2R & NASA GISS & $2.00^{\circ} \times 2.50^{\circ}$ \\
7 & INM-CM4* & INM & $2.0^{\circ} \times 1.50^{\circ}$ \\
8 & IPSL-CM5A-LR & IPSL & $3.75^{\circ} \times 1.90^{\circ}$ \\
9 & IPSL-CM5A-MR & IPSL & $2.50^{\circ} \times 1.25^{\circ}$ \\
10 & MIROC5 & MIROC & $1.40^{\circ} \times 1.40^{\circ}$ \\
11 & MRI-CGCM3* & MRI & $1.1^{\circ} \times 1.2^{\circ}$ \\
\hline
\end{tabular}

Horizontal resolution is in $d \lambda \times d \phi$. The model name and their centre acronyms are available at http://cmip-pcmdi.llnl.gov/CMIP5/docs/ CMIP5_modeling_groups.pdf

*A total of 20 years data was available for piControl scenario 
stream variability can also be explored by calculating the jet persistence; see Barnes and Hartmann (2010a, b) and HA13. The jet persistence (in days) following HA13 is defined as the area under the auto-correlation curve of the jet latitude between 0 and 10 days. These statistics of the jet latitude and wind speed are applied to compare CMIP5 simulations with ERA40 and CMIP3.

\section{Results and discussion}

We first present a brief overview of the jet structure in ERA40. The reader is directed to Woollings et al. (2010) and HA13 for more details. The comparison of CMIP5 historical simulations with ERA40 and future simulations with historical runs is presented afterwards. Finally, the comparison of CMIP3 and CMIP5 is presented for each model.

\subsection{Past climate 1957-2002}

\subsubsection{Re-analysis}

Figure 1 of HA13 and Woollings et al. (2010) summarizes the jet latitude properties for ERA40. Briefly, the northsouth variation in latitude is about $5^{\circ}$ and is consistent with the meridional temperature gradients. The jet is persistent and always stays within the preferred latitudes, i.e. $30-60^{\circ} \mathrm{N}$ (Fig. 1c of HA13). The winter jet latitude PDF (Fig. 1d of HA13) shows three preferred positions of the North Atlantic jet, (1) south of the climatological mean of the jet (southern mode), (2) close to the climatological mean of the jet (central mode) and (3) north of the climatological mean of the jet (northern mode). These three modes correspond respectively to the Greenland blocking (GB) high, a low pressure centre and a high pressure centre over the northern North Atlantic (Woollings et al. 2010). The distribution of jet latitude in (a) Can-ESM2

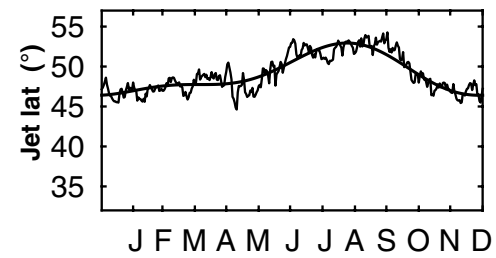

(d) GFDL-ESM2G

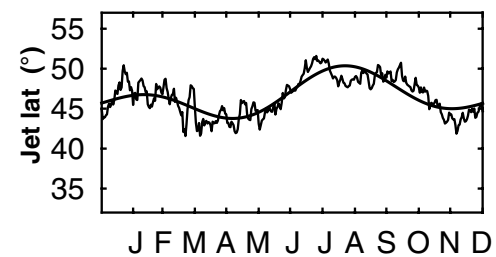

(g) INM-CM4

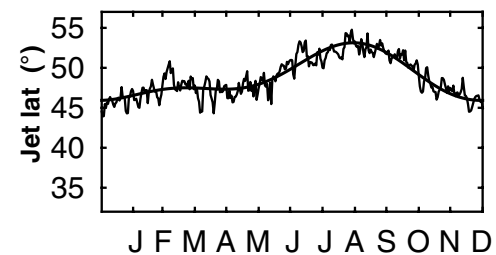

(j) MIROC5

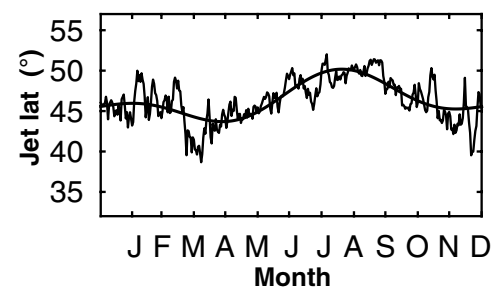

(b) CNRM-CM5

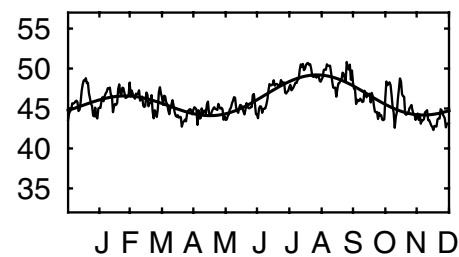

(e) GFDL-ESM2M

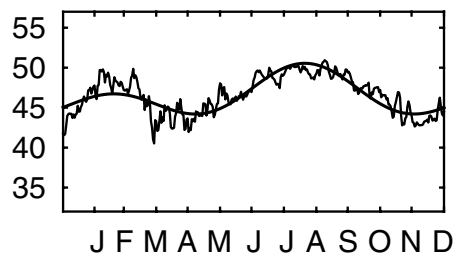

(h) IPSL-CM5A-LR

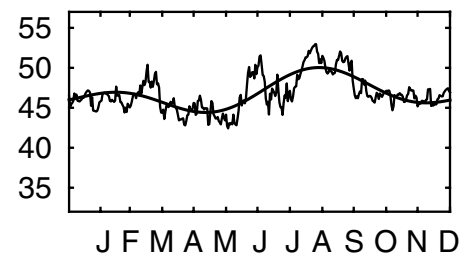

(k) MRI-CGCM3

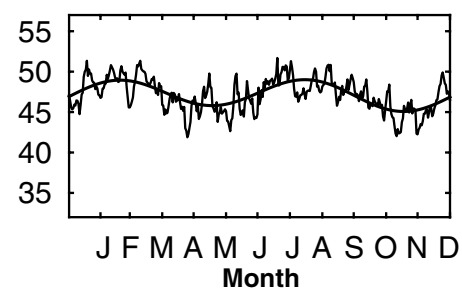

(c) CSIRO-MK3.6-0

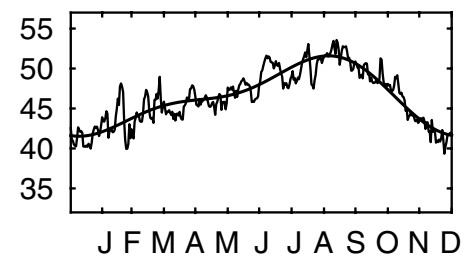

(f) GISS-E2R

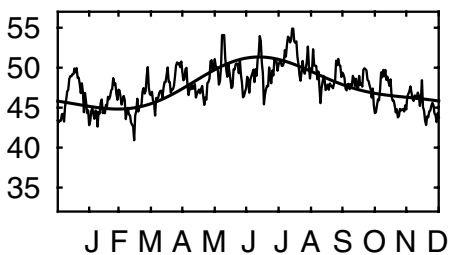

(i) IPSL-CM5A-MR

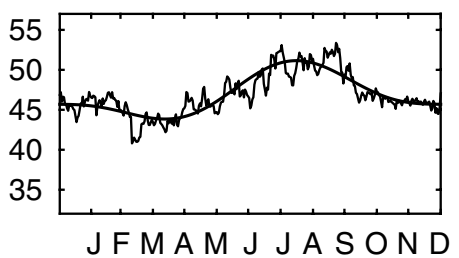

ERA-40

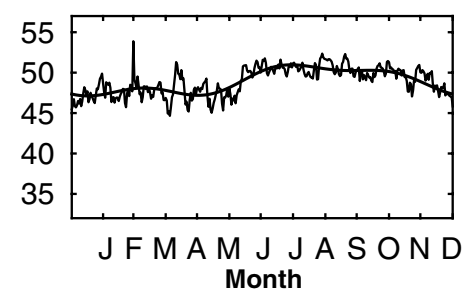

Fig. 1 Mean and smoothed jet latitude seasonal cycle for Historical simulations in CMIP5 for the 11 selected models and ERA40 (bottom right panel) 
CMIP3 integrations shows a more equatorward jet than the poleward jet (Barnes and Hartmann 2010b, HA13).

\subsubsection{CMIP5 GCMs}

The mean and smoothed seasonal cycles in the Historical simulations along with ERA40 are presented in Fig. 1. Most of the models analysed in this study are able to reproduce the phase of the jet latitude seasonal cycle but there are differences at individual level, e.g. variability around the smooth seasonal cycle is higher in CMIP5 models as compared to ERA40. This higher variability in CMIP5 GCMs might be related to (1) different time lengths of comparison data sets (25 year in GCMs vs 45 years in ERA40) and (2) CMIP5 model discrepancies; and certainly deserves further attention. The seasonality of jet latitude from Can-ESM2, CNRM-CM5 and INM-CM4 is relatively close to ERA40. The seasonal variation in the amplitude of jet latitude is $5^{\circ}$ in ERA40, clearly there is an overestimation in this latitudinal variation from all CMIP5 GCMs. A latitudinal change of $10^{\circ}$ is observed for CSIRO-MK3.6-0 and GISS-E2R. The seasonal anomalies in CMIP5 GCMs with respect to ERA40 are shown in Fig. 2. The negative biases in early winter (November and December) from most of the GCMs imply an equatorward shifted jet. The seasonal cycle anomaly bias is $1^{\circ}$ $-2^{\circ}$ in all GCMs with few exceptions of CSIRO-MK3.6-0 and GISS-E2R. The biases in the CMIP5 GCMs are smaller than those of CMIP3 GCMs where a bias of $5^{\circ}$ was reported (HA13). These biases in individual models are compared in later section. Both the phase and amplitude of jet latitude seasonal cycle in 20th century simulations from CMIP5 have improved from that of CMIP3 (see Fig. 3 of HA13) with respect to ERA40. Equatorward (poleward) jet latitude bias is observed (Fig. 2) in summer (winter), which was also reported by HA13 for CMIP3. This equatorward bias in jet seasonality from CMIP models was also reported by Kidston and Gerber (2010) and Woollings and Blackburn (2012). (a) Can-ESM2

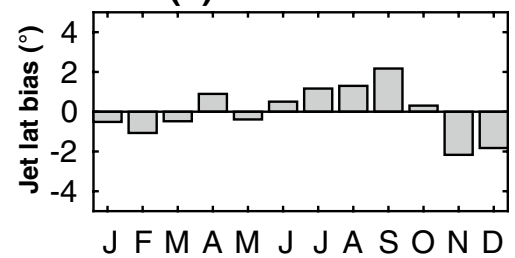

(d) GFDL-ESM2G

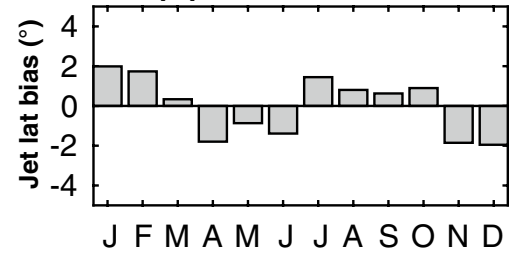

(g) INM-CM4

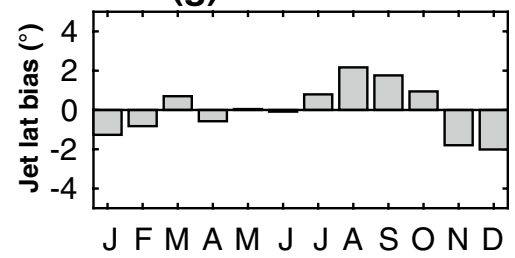

(j) MIROC5

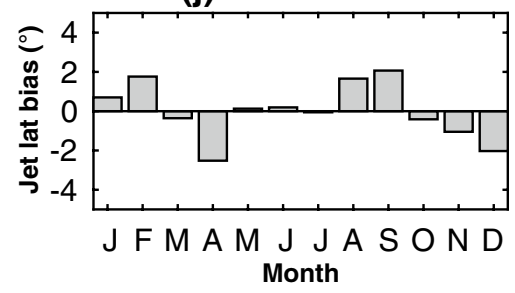

(b) CNRM-CM5

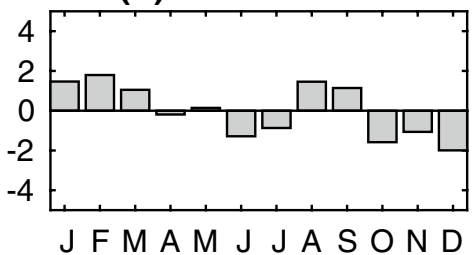

(e) GFDL-ESM2M

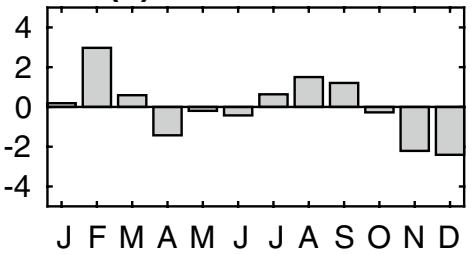

(h) IPSL-CM5A-LR

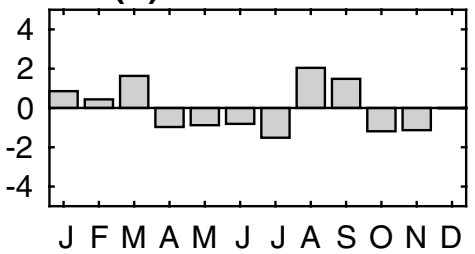

(k) MRI-CGCM3

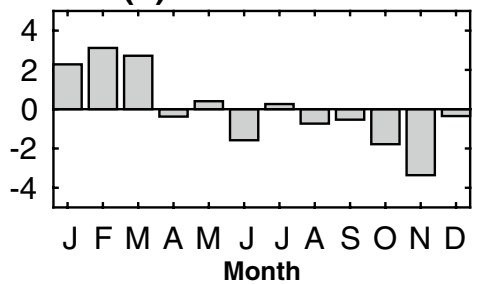

(c) CSIRO-MK3.6-0

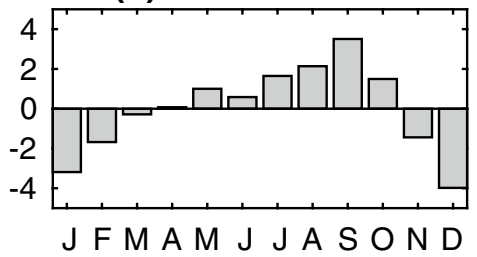

(f) GISS-E2R

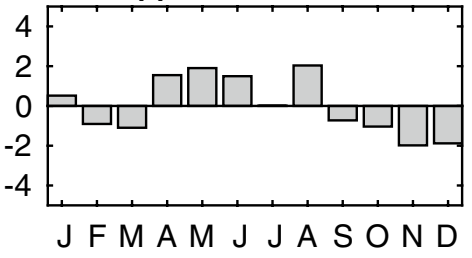

(i) IPSL-CM5A-MR

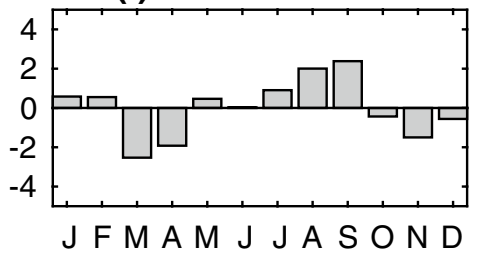

Fig. 2 North Atlantic jet stream latitude mean seasonal cycle anomaly bias $\left({ }^{\circ}\right)$ from Historical simulation in CMIP5 with respect to ERA40. The seasonal cycle anomaly is computed by subtracting the annual mean value of model (ERA40) from the model (ERA40) 
(a) Can-ESM2

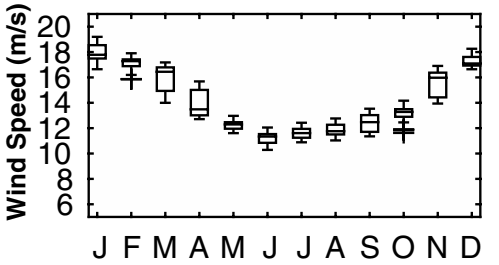

(d) GFDL-ESM2G

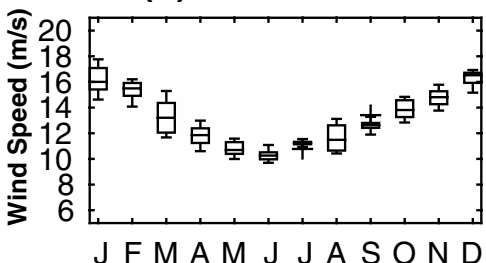

(g) INM-CM4

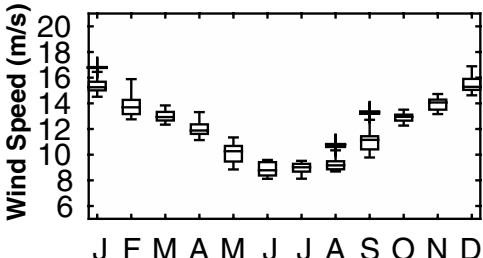

(j) MIROC5

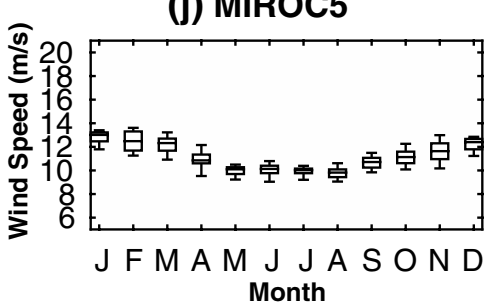

(b) CNRM-CM5

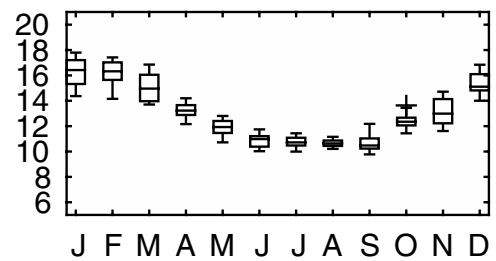

(e) GFDL-ESM2M

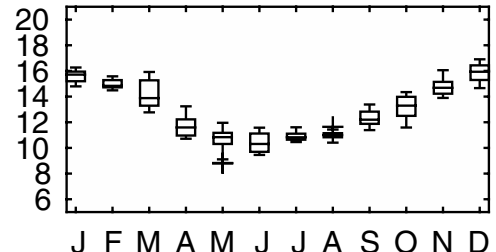

(h) IPSL-CM5A-LR

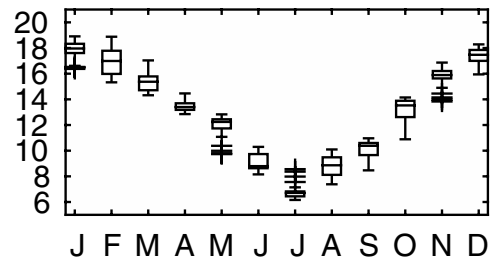

(k) MRI-CGCM3

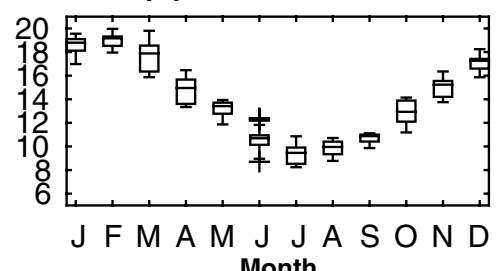

(c) CSIRO-MK3.6-0

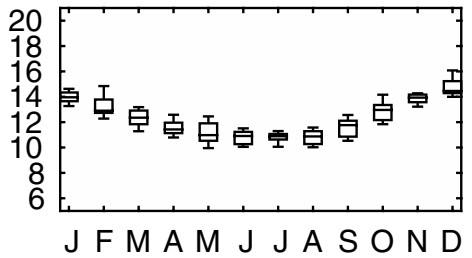

(f) GISS-E2R

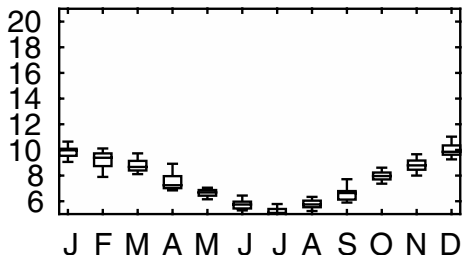

(i) IPSL-CM5A-MR

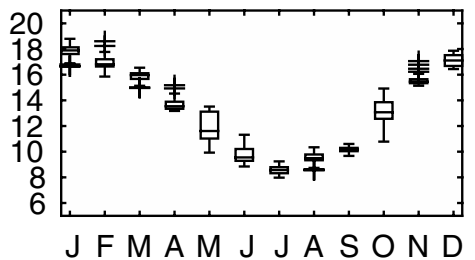

ERA-40

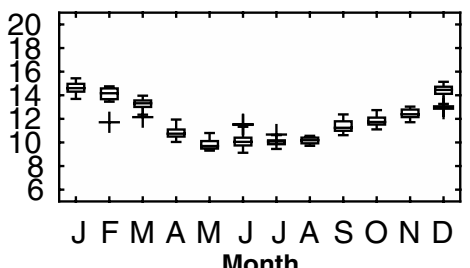

Fig. 3 Boxplot of daily mean wind speed (m/s) from Historical simulations in CMIP5 and ERA40 (bottom right panel)

The speed of the jet from these models is also analysed for the historical simulations. The seasonal cycle of wind speed is shown in (Fig. 3). The majority of the CMIP5 GCMs overestimate the amplitude of the mean seasonal cycle compared to the ERA40 for the historical simulations. There are some models for which the mean seasonal cycle of wind speed is comparable to ERA40 (e.g. Can-ESM2, MIROC5 and INMCM4). The comparison of individual models from CMIP5 and CMIP3 for mean seasonal cycle anomaly of wind speed from the Historical simulations show higher biases for the CMIP5 (see Online Resources Fig. OR5). The biases in the mean seasonal cycle of wind speed for Historical simulations of CMIP5 GCMs show overestimation in the winter and underestimation during the summer season, as compared to ERA40 (Fig. 4).

The PDF kernel estimate of winter daily jet latitude in Historical CMIP5 simulations is shown in Fig. 5. A similar PDF is obtained for piControl simulations (not shown). None of the CMIP5 models is able to fully simulate the tri-modal structure of the jet. The majority of the models overestimate the central mode of the jet, while they underestimate both the southern and the northern mode of the jet (see Online Resources Fig. OR1). The underestimation of the central mode is strongest in the case of MIROC5. DunnSigouin and Son (2013) also reported an underestimation of Euro-Atlantic blocking frequency in CMIP5 simulations for winter.

\subsection{Future climate 2076-2099 via RCP4.5 and RCP8.5 scenarios}

The response to global warming under RCP4.5 and RCP8.5 is examined in CMIP5 GCMs for jet latitude and wind speed along with the PDF differences. These results are described in a complete section in the Online Resource Section 1. However the main findings are: (1) the majority of the models support the poleward shift of jet under global warming, (2) reduction of multimodality in the jet latitude PDF and 
(a) Can-ESM2

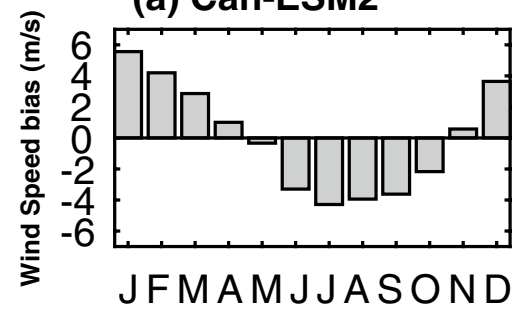

d.) GFDL-ESM2G

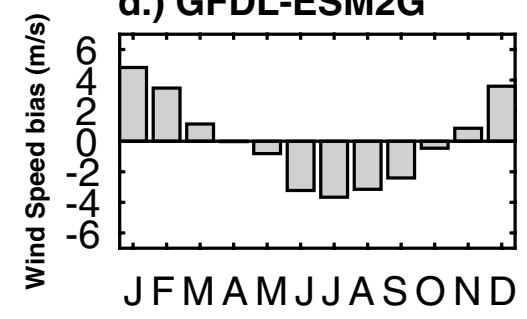

g.) INM-CM4

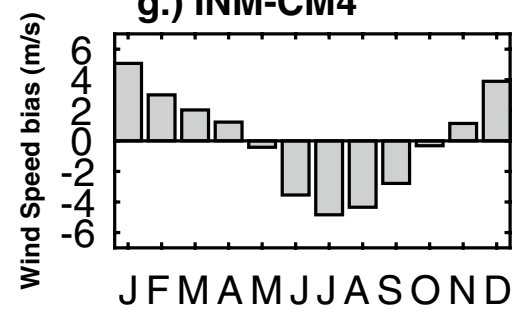

j.) MIROC5

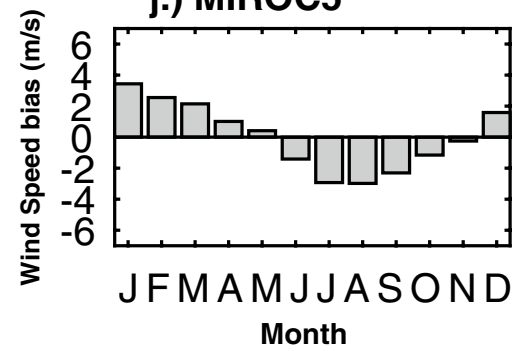

b.) CNRM-CM5

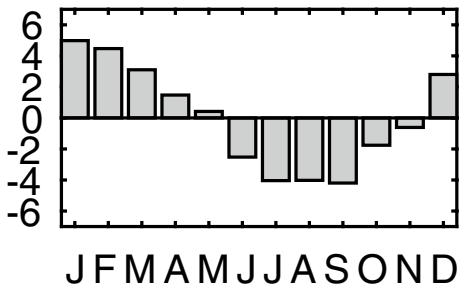

e.) GFDL-ESM2M

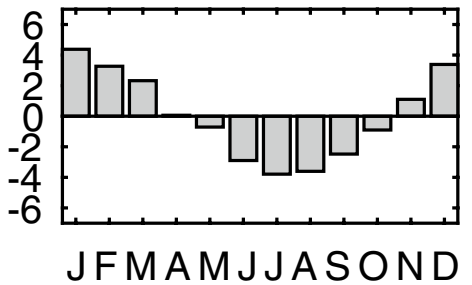

h.) IPSL-CM5A-LR

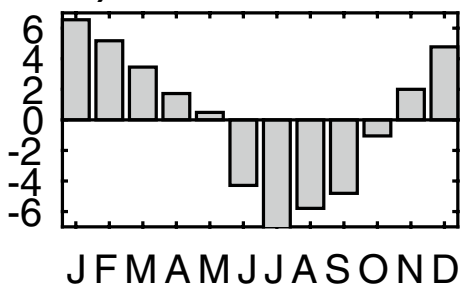

k.) MRI-CGCM3

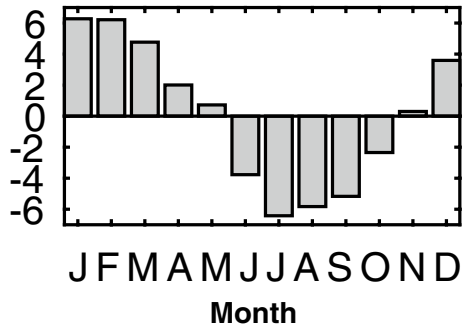

c.) CSIRO-MK3.6-0

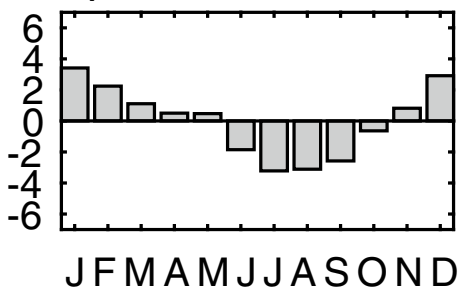

f.) GISS-E2R

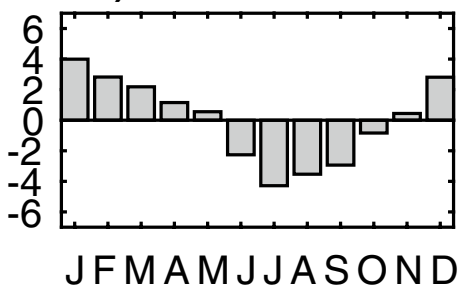

i.) IPSL-CM5A-MR

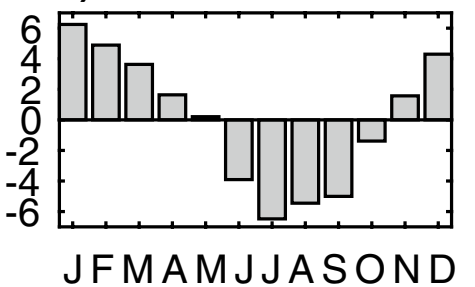

Fig. 4 North Atlantic jet stream wind speed mean seasonal cycle anomaly bias (m/s) from Historical simulation in CMIP5 with respect to ERA40. The seasonal cycle anomalies are obtained by removing the mean seasonal cycle

(3) increased wind speed of the North Atlantic jet stream under two RCPs.

The effects of climate change on the jet latitude and wind speed can be examined by analysing the higher-order moments of their pdfs, i.e., skewness and excess kurtosis, related to non-Gaussianity in weather and climate (Hannachi et al. 2017; Sura and Hannachi 2015; Christiansen 2015) between the forcing scenarios and control run as in HA13. The well known feature of poleward shift of the jets under global warming can be investigated by analysing the skewness differences between control and forced simulations (HA13). The decrease in the skewness under climate change is associated with the poleward shifted jet as shown by Barnes and Polvani (2013) for CMIP5 RCP8.5 simulations. The difference in the skewness in the two forcing scenarios for CMIP5 models used here is very small (Fig. 6a).
The values of skewness differences from these simulations show that the warming effect is not robust for individual models. However, the ensemble mean change of skewness is negative (i.e. -0.07 and -0.12 respectively for RCP4.5 and RCP8.5), implying a less skewed jet latitude distribution as global warming response. Barnes and Polvani (2013) has also shown that for CMIP5 GCMs, the poleward shifted jet is less skewed. The changes in the jet latitude skewness from CMIP3 GCMs show similar results (HA13).

Excess kurtosis has also been used to examine the PDFs changes. A negative kurtosis is synonymous with PDF flatness, which provides in general a potential for jet persistence but also jet multimodality (HA13). The excess kurtosis difference between the RCPs and piControl simulation is shown in Fig. 6. Three models for RCP 8.5 scenario have decreased excess kurtosis as compared to two models from 
(a) Can-ESM2

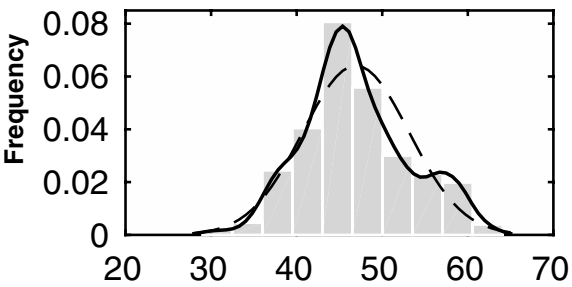

(d) GFDL-ESM2G

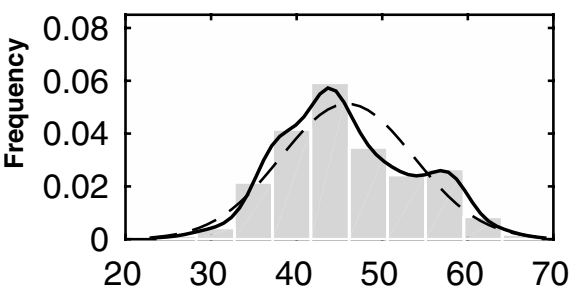

(g) INM-CM4

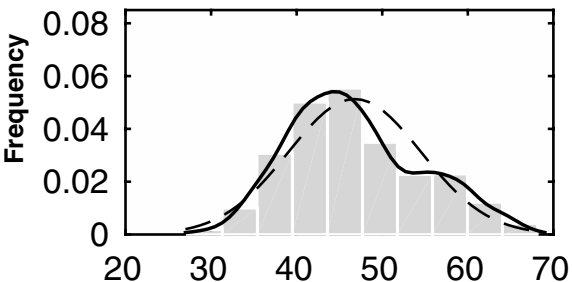

(j) MIROC5

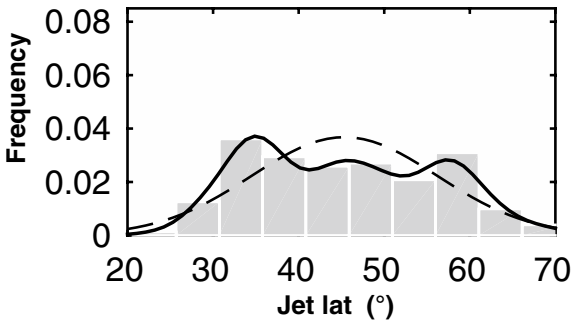

(b) CNRM-CM5

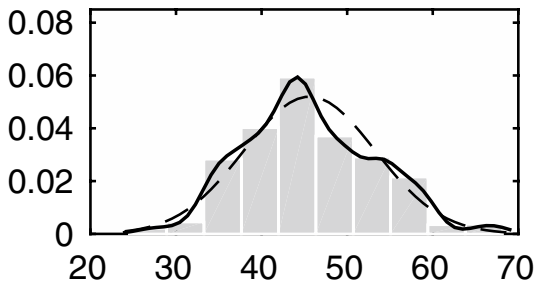

(e) GFDL-ESM2M

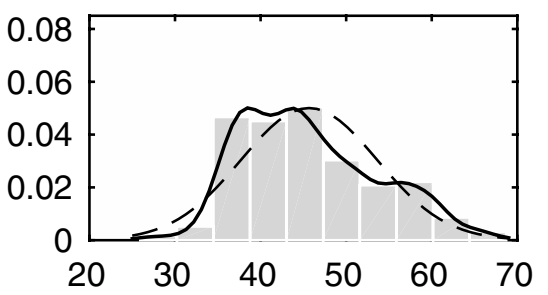

(h) IPSL-CM5A-LR

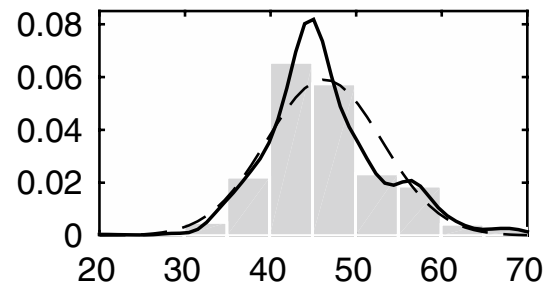

(k) MRI-CGCM3

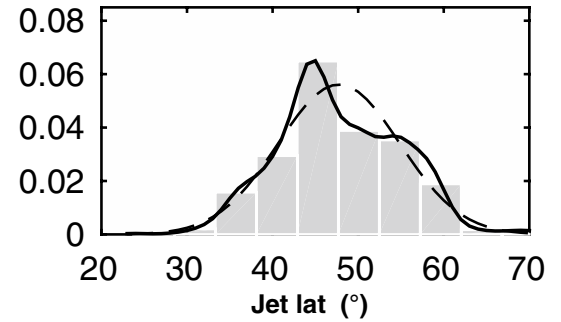

(c) CSIRO-MK3.6-0

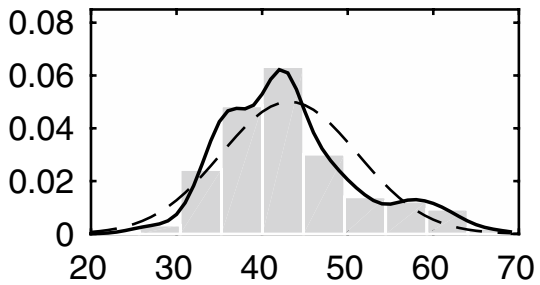

(f) GISS-E2R

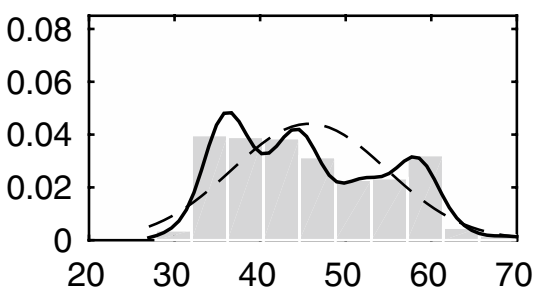

(i) IPSL-CM5A-MR

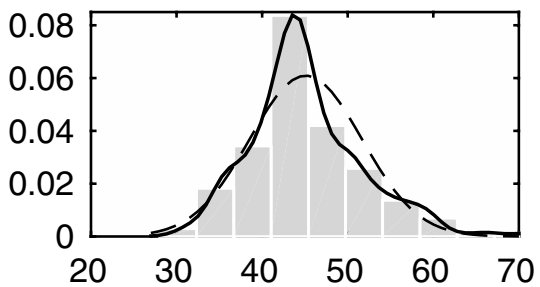

ERA-40

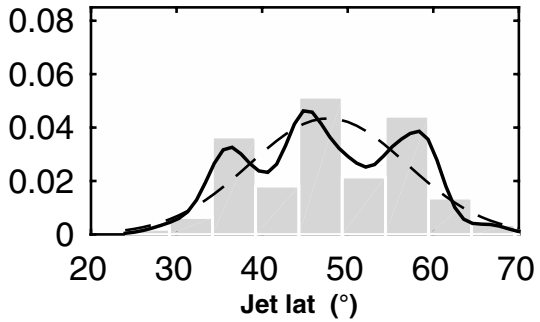

Fig. 5 Histogram and kernel estimate PDFs of the DJFM jet latitude time series from Historical simulations in CMIP5 and ERA40 (bottom right panel). The smoothing parameter for kernel estimate (solid line) is $h=1.06 \sigma n^{-1 / 5}$, with $\sigma$ and $n$ respectively the standard deviation and the sample size of the time series. The normal density function fitted to the total jet latitude time series is also shown (dashed)
RCP4.5 (Fig. 6b), suggesting a decrease in the multimodality of CMIP5 models under RCP8.5. The ensemble mean change of excess kurtosis is positive (Fig. 6b) for RCP8.5 only $\quad\left(\mathrm{RCP} 4.5_{\text {mean }}=-0.026, \mathrm{RCP} 8.5_{\text {mean }}=2.8 \times 10^{-4}\right)$. The individual models show different responses, but almost half of the models show increase under both the scenarios. Hence the PDFs of these models have tendency to become more unimodal structure under the external forcing effects suggesting a more broad jet, consistent with the changes in PDFs discussed earlier.

The mean jet latitude is also further examined by testing the relationship with other moments such as standard deviation, skewness and excess kurtosis. These statistics are computed for the mean winter (DJFM) from each model for each scenario i.e. one value for each model. A set of four simulations (Historical, PiControl, RCP4.5 and RCP8.5; 11 GCMs in each) together with the ERA-40 make a total of 45 data points. Figure 7a shows a scatter plot of the mean jet latitude versus standard deviation from each model with four forcing scenarios. There is only a weak (but significant) correlation of -0.21 between mean jet latitude and standard deviation of the jet latitude. A negative correlation entails a small variability of the jet latitude as the jet shifts poleward. These findings do not agree with HA13, since they reported a significantly negative correlation of -0.42 in CMIP 3 models. The individual models have different correlations, for example, there are five models (CNRM-CM5, two GFDL models, GISS-E2R and MRI-CGCM3) with negative 
Fig. 6 Departure, from the piControl simulation, of a skewness and $\mathbf{b}$ kurtosis of the jet latitude for RCP4.5 (white circles) and RCP8.5 (black circles). The shading represents the $5 \%$ significance level using Student's $t$-test
Fig. 7 Mean jet latitude versus a standard deviation, $\mathbf{b}$ skewness and $\mathbf{c}$ excess kurtosis from all selected CMIP5 GCMs simulations under four scenarios and ERA40 for DJFM time series. The correlation coefficients significant at 5\% significance level are shown in each panel

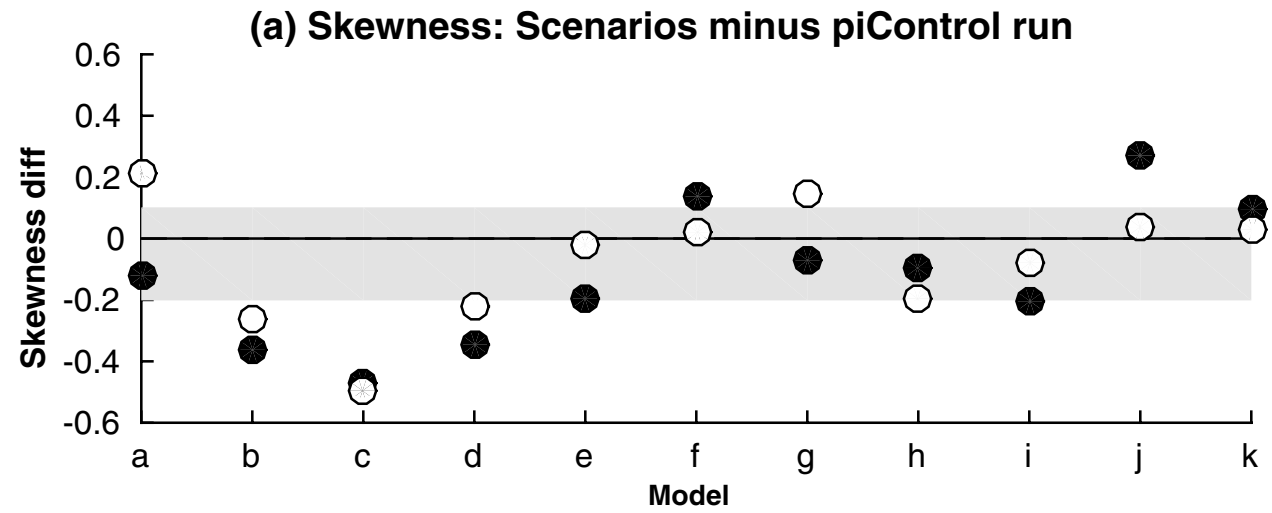

(b) Kurtosis: Scenarios minus piControl run

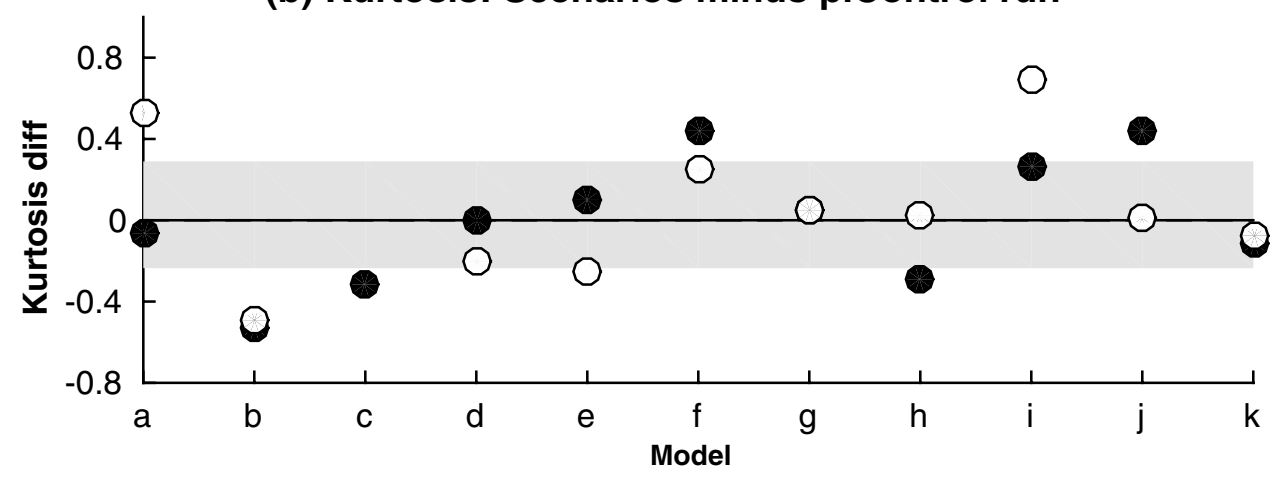

(a) Mean jet vs Standard deviation

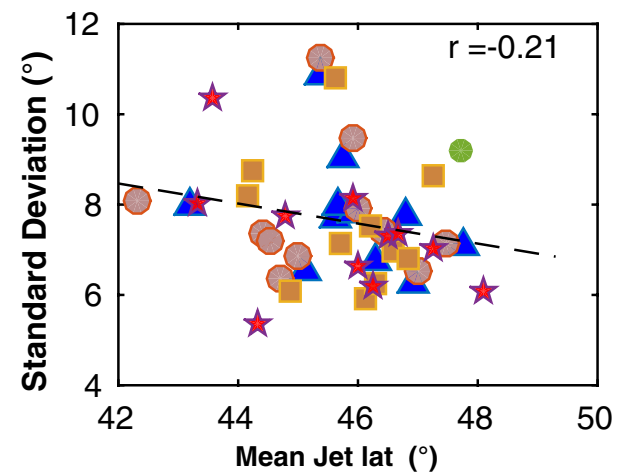

(b) Mean jet vs Skewness

(c) Mean jet vs Excess kurtosis

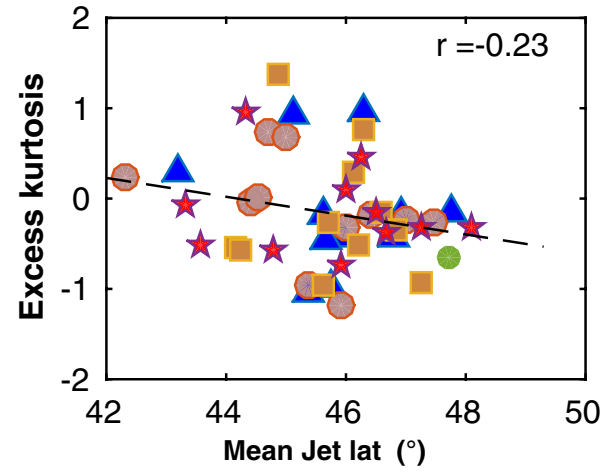

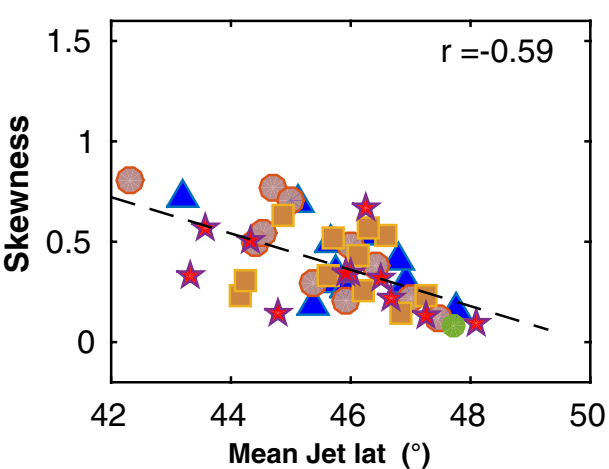

Historical
piControl
RCP4.5
$\star$
RCP8.5
ERA40 
correlations. The other models have positive correlation, which implies that the overall weak correlation might be caused by individual performance or characteristics of each model. Barnes and Hartmann (2011) found negative correlation in a barotropic model where they observed a narrowing of PDF histograms for the poleward jet. The jet variability is transitioned from a meridional shift to a more change of jet speed. In the current study, the CMIP5 models show more narrowing of PDFs in Historical simulations compared to ERA40 and an equatorward shifted jet. These are not in full agreement with the negative correlation between the mean jet latitude and standard deviation.

The relationship between the mean jet latitude and skewness (Fig. 7b) shows that the ERA40 value in winter for mean jet latitude and skewness are $47.72^{\circ}$ and 0.078 respectively. Most models are more positively skewed and shifted equatorward. The slope of the regression line is significantly different from zero at $5 \%$ level. This implies that the relationship between equatorward (poleward) jet and the more(less) positive skewed jet latitude is consistent among all the model simulations. This result is in agreement with the findings of Barnes and Hartmann (2010a). They suggested that the poleward shifted jet can be limited by the reduction of wave breaking near the pole and the eddy feedback. The midlatitude jets also have low PDF towards subtropics because of the presence of strong subtropical winds (Barnes and Polvani 2013). Therefore, the PDFs become more symmetric when the mean jets move poleward.

The scatter plot of mean jet latitude and excess kurtosis (Fig. $7 \mathrm{c}$ ) shows a mean value of -0.65 for excess kurtosis for the winter jet latitude time series in ERA40. The slope of the regression line is significantly different from zero at the 5\% significance level, reflecting the fact that the PDFs are less peaked when the jet moves poleward. In fact, the excess kurtosis even turns to a negative value when the jet latitude is poleward of about $47^{\circ} \mathrm{N}$. It is because the blocking events can occur frequently in the northern part of North Atlantic, i.e. high-latitude blocking (Woollings and Hoskins 2008). Consequently, the jet is diverted to the southern position meaning a more persistent equatorward jet.

The jet persistence was related to the jet latitude in CMIP3 models as well as with the other statistical metrics like standard deviation, skewness and excess kurtosis (Barnes and Hartmann 2010b; Kidston and Gerber 2010, HA13). Generally, these features in the CMIP5 GCMs investigated here are less significant or not entirely coherent with those in CMIP3 models. Figure 8 shows a comparison of the jet persistence with the mean jet latitude and the skewness. There is negative correlation between the mean jet latitude and the persistence which implies that persistence decreases as the jet is shifted poleward to its climatological position (Fig. 8a). The persistence and skewness show positive correlation for CMIP5 models (Fig. 8b), with slope of regression line equal to 0.737 days $/^{\circ}$. The individual models show a positive correlation between the persistence and skewness. The skewness reduction corresponds to a decrease in the jet persistence. This shows a strong agreement with the previous findings that both skewness and persistence decrease for a poleward shifted jet. Hence, poleward shifted jets tend to have a less positive skewness and therefore the persistence is decreased.

\section{Discussion of the comparison of CMIP3 and CMIP5 GCMs}

We present here a brief summary of the comparison between CMIP3 and CMIP5 simulations of the jet statistics. The individual models are compared for jet latitude, speed and frequency biases for winter season.

The comparison of individual models from CMIP3 and CMIP5 integrations with respect to ERA40 for jet latitude (a) Persistence vs Mean jet

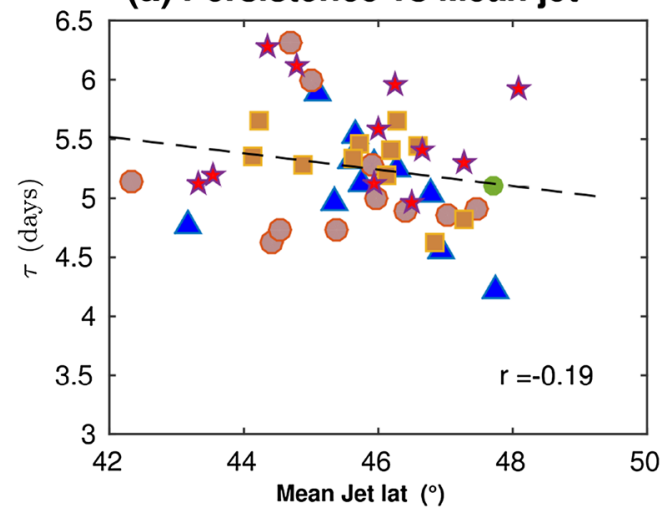

(b) Persistence vs Skewness

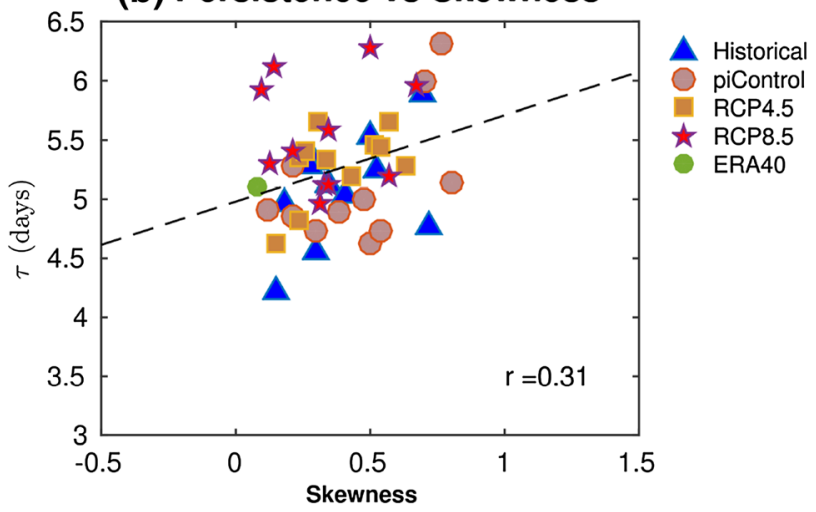

Fig. 8 The jet persistence versus a mean jet latitude and $\mathbf{b}$ mean skewness from all selected CMIP5 GCMs simulations under four scenarios and ERA40 for DJFM time series. The correlation coefficients significant at 5\% significance level are shown in each panel 


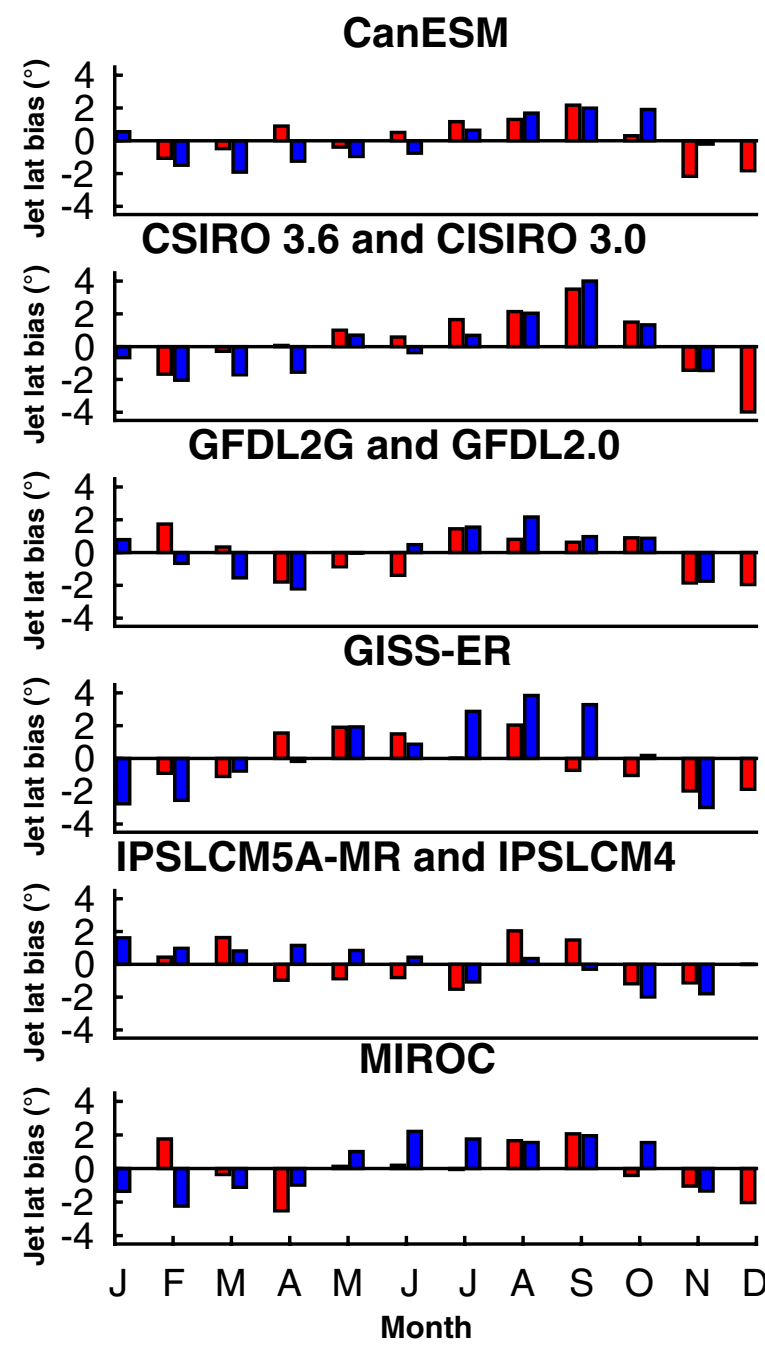

Fig. 9 North Atlantic jet stream latitude mean seasonal cycle anomaly bias $\left(^{\circ}\right)$ from Historical with respect to ERA40 in individual GCM. The red and blue colors represent respectively CMIP5 and CMIP3 GCM. There are two available models from IPSL (CSIRO)

mean seasonal cycle anomaly is presented in Fig. 9. The ensemble mean bias from the CMIP3 and CMIP5 historical simulations with respect to ERA40 is respectively $-2.43^{\circ}$ and $-1.79^{\circ}$. Thus, resulting in a reduced bias for CMIP5 historical simulations. However, there is no extraordinary improvement in simulating the characteristics of the North Atlantic eddy-driven jet, by the tested CMIP5 models. The jet latitude mean seasonal cycle anomaly is still about $\pm 2^{\circ}$ which is comparable to the CMIP3 models. For example CanESM in CMIP3 shows an equatorward shifted jet in winter and a poleward shifted jet in summer but these features are not robust for CMIP5 integrations. In addition, the GFDL models show a poleward shifted jet in late summer and an equatorward shifted jet in early winter for both CMIP3 and CMIP5. The jet latitude bias is seasonally dependent in both CMIPs, although slightly less in CMIP5. The differences

\section{CNRM}

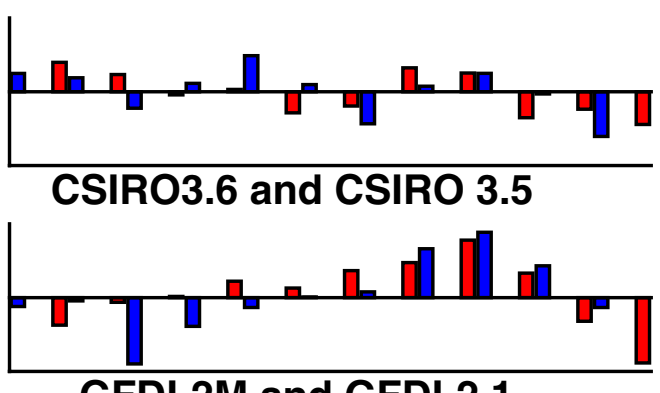

GFDL2M and GFDL2.1
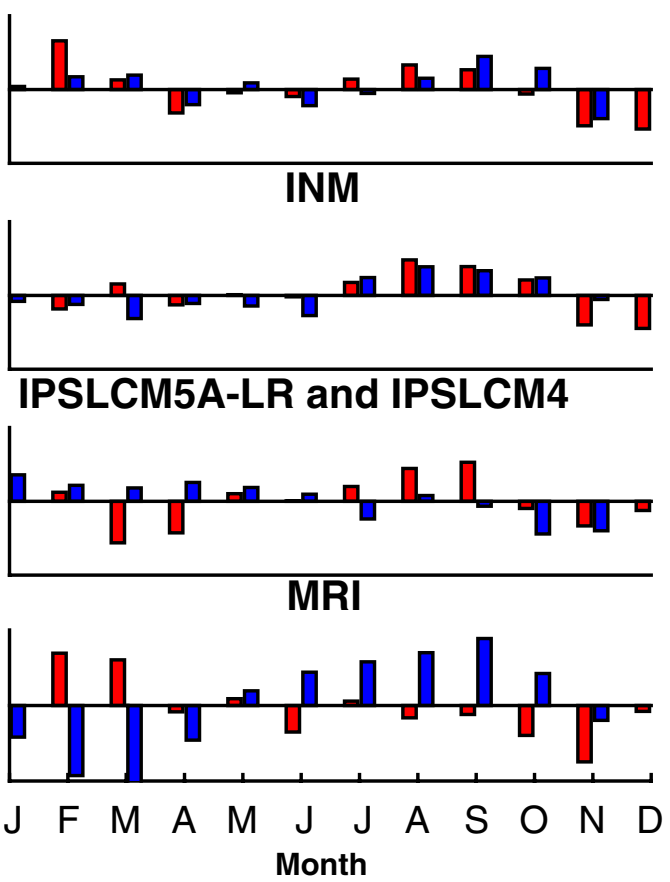

for CMIP5 (CMIP3). These two GCMs from each centre are compared to the one from previous (CMIP3) or current (CMIP5) version of that GCM

between the CMIP3 and CMIP5 models are greater in the seasonality of wind speed (See Online Resource Fig. OR5). The analysed models for both CMIP5 and CMIP3 show a robust feature of overestimated wind speed during summer and underestimated wind speed in winter. Besides the preserved seasonal patterns, no improvement can be observed in the tested models.

There is no great improvement in simulating the winter jet latitude PDF in CMIP5. The PDF differences of Historical simulations with ERA40 reanalysis in CMIP3 and CMIP5 models range between -0.04 and 0.04 (Fig.10). Most of the GCMs in CMIP5 experiments overestimate the central mode of the eddy-driven jet. There is a slight improvement for the accuracy of jet distribution in the NOAA GFDL and NASA GISS models. The vertical resolution contributes effectively in reducing the model bias 

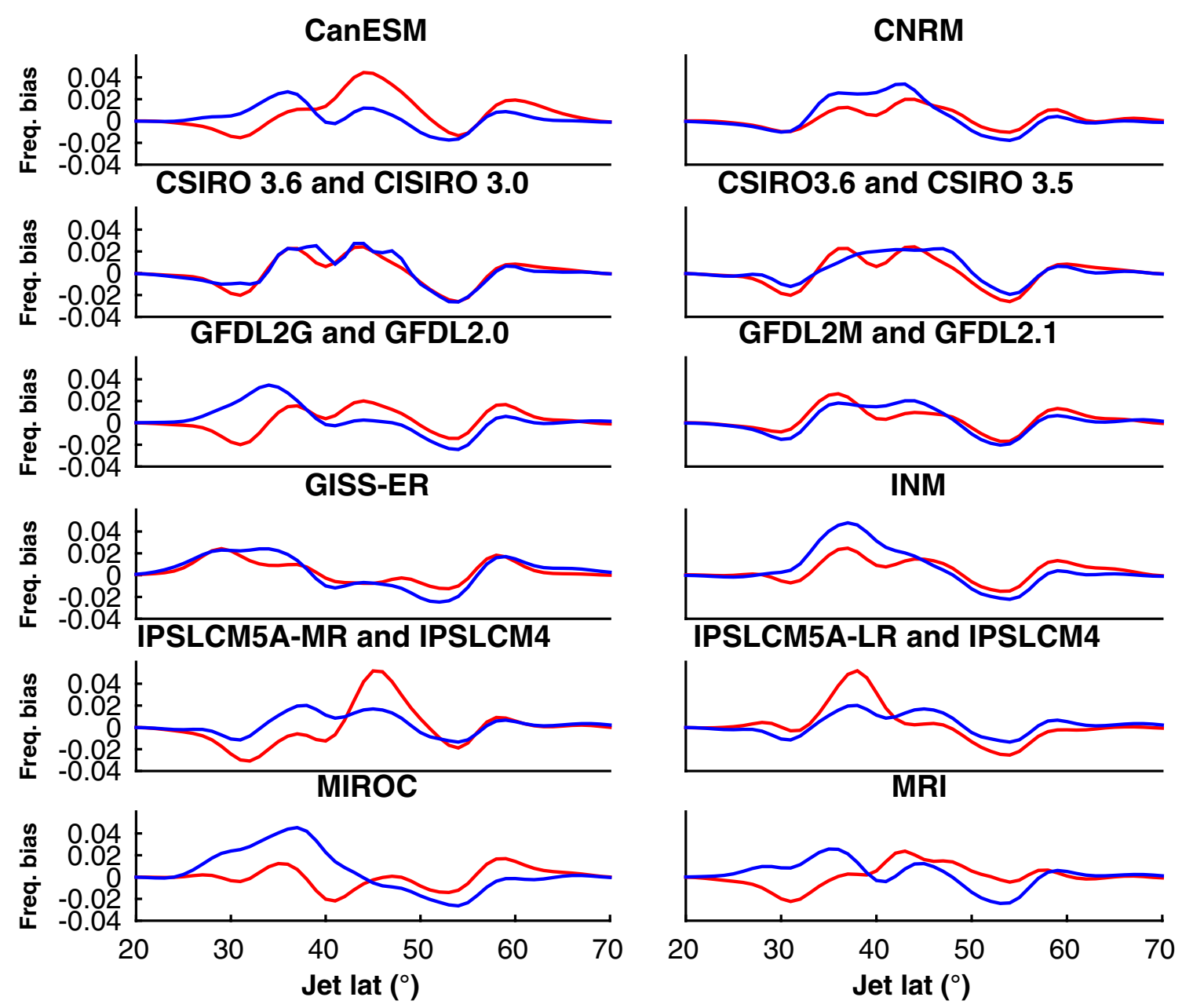

Fig. 10 Comparison of winter (DJFM) North Atlantic jet stream latitude time series kernel estimate PDF bias for the historical simulations for individual models in CMIP5 and CMIP3. The red and blue

colors respectively represent CMIP5 and CMIP3 values. The biases are calculated w.r.t ERA40 winter daily jet latitude time series kernel estimate PDF

(Scaife and Knight 2008). The improvements in CMIP5 models may be attributed to the higher resolution but both horizontal and vertical resolutions in the GFDL models (CMIP3 and CMIP5) are similar and the only enhancement is an advanced land model, which resulted in reduced frequency differences.

A lower frequency difference between these models (e.g. CSIRO, GFDL, GISS-ER etc) and ERA40 at northern position seems to agree with the fact that high resolution and detailed orography in CMIP5 increases the European blocking frequency. In the IPSL models, the patterns are more peaked at central position and amplified in the CMIP5 experiments. The jet tends to stay around the central region of North Atlantic when the blocking frequency is low.

\section{Conclusion}

The performance of a number of CMIP5 models has been investigated by comparing the jet latitude and wind speed to those obtained from ERA40 and the CMIP3 simulations. The phase of the mean seasonal cycle of jet latitude and wind speed are comparable to the reanalysis data. However, an overestimation of wind speed for winter months is observed in the majority of the models. Furthermore, most of the models cannot simulate the trimodal structure of the jet latitude PDF. The PDFs are in fact too narrow and peaked. This might be related to the overall underestimation of blocking events in CMIP5 models.

Climate change projections under two scenarios, RCP4.5 and RCP8.5, are computed with respect to 20th century 
Historical runs of CMIP5. There is a prominent response of global warming under RCP8.5 where the jet latitude distribution is slightly poleward shifted and peaked. This feature is further confirmed by finding the difference of skewness and excess kurtosis between the forcing scenarios and the control run. The jet is both strengthened and poleward shifted under RCP8.5 forcings. However, it is noticed that individual models have a varying response under the different forcing scenarios.

Further analysis of mean statistics (jet latitude, skewness, excess kurtosis) from each model under each forcing scenario for the winter season, shows a poleward shifted jet as a response to global warming. The variability around the mean jet latitude position is also projected to be reduced in the future climate. There is a weak correlation between the mean jet latitude and jet latitude standard deviation. Both skewness and the jet latitude persistence of the jet latitude decrease for a poleward jet.

Regarding the overall performance of CMIP5 and CMIP3, there does not seem to be significant difference in the seasonality of jet latitude; although a slight improvement for the amplitude and phase of the jet latitude mean seasonal cycle is observed in the CMIP5 models. The ensemble mean bias from the CMIP3 and CMIP5 historical simulations with respect to ERA40 is respectively $-2.43^{\circ}$ and $-1.79^{\circ}$. However, the wind speed is overestimated by most of the CMIP5 models in winter months as compared to ERA40. The PDFs of jet latitude in CMIP5 models are more poleward and peaked as compared to those from the CMIP3 models.

Acknowledgements We acknowledge the World Climate Research Programme's Working Group on Coupled Modelling, which is responsible for CMIP, and we thank the climate modeling groups (listed in Table 1 of this paper) for producing and making available their model output. For CMIP the US Department of Energy's Program for Climate Model Diagnosis and Intercomparison provides coordinating support and led development of software infrastructure in partnership with the Global Organization for Earth System Science Portals. The computations were performed on resources provided by the Swedish National Infrastructure for Computing (SNIC) at the National Supercomputing Centre (SNC). We would like to thank the two anonymous reviewers for their constructive comments that helped to improve this paper.

Open Access This article is distributed under the terms of the Creative Commons Attribution 4.0 International License (http://creativecommons.org/licenses/by/4.0/), which permits unrestricted use, distribution, and reproduction in any medium, provided you give appropriate credit to the original author(s) and the source, provide a link to the Creative Commons license, and indicate if changes were made.

\section{References}

Anstey JA, Davini P, Gray LJ, Woollings TJ, Butchart N, Cagnazzo C, Christiansen B, Hardiman SC, Osprey SM, Yang S (2013) Multi-model analysis of Northern Hemisphere winter blocking: model biases and the role of resolution. J Geophys Res Atmos 118:3956-3971. doi:10.1002/jgrd.50231

Barnes EA, Hartmann DL (2010a) Testing a theory for the effect of latitude on the persistence of eddy-driven jets using CMIP3 simulations. Geophys Res Lett. doi:10.1029/2010GL044144

Barnes EA, Hartmann DL (2010b) Influence of eddy-driven jet latitude on North Atlantic jet persistence and blocking frequency in CMIP3 integrations. Geophys Res Lett. doi:10.1029/201 0GL045700

Barnes EA, Hartmann DL (2011) Rossby wave scales, propagation, and the variability of eddy-driven jets. J Atmos Sci 68(12):2893-2908. doi:10.1175/JAS-D-11-039.1

Barnes EA, Polvani LM (2013) Response of the midlatitude jets, and of their variability, to increased greenhouse gases in the CMIP5 models. J Clim 26(18):7117-7135. doi:10.1175/ JCLI-D-12-00536.1

Barnes EA, Polvani LM (2015) CMIP5 projections of Arctic amplification, of the North American/North Atlantic circulation, and of their relationship. J Clim 28:5254-5271. doi:10.1175/ JCLI-D-14-00589.1

Ceppi P, Hartmann DL (2013) On the speed of the eddy-driven jet and the width of the Hadley cell in the Southern Hemisphere. J Clim 26:3450-3465. doi:10.1175/JCLI-D-12-00414.1

Christiansen B (2015) The role of the selection problem and nonGaussianity in attribution of single events to climate change. J Clim 28:9873-9891. doi:10.1175/JCLI-D-15-0318.1

Dee DP et al (2005) The ERA-Interim reanalysis: configuration and performance of the data assimilation system. Q J R Meteorol Soc 137:553-597. doi:10.1002/qj.828

Sigouin ED, Son SW (2013) Northern Hemisphere blocking frequency and duration in the CMIP5 models. J Geophys Res Atmos 118(3):1179-1188. doi:10.1002/jgrd.50143

Franzke C, Woollings T (2011) On the persistence and predictability properties of North Atlantic climate variability. J Clim 24:466472. doi:10.1175/2010JCLI3739.1

Furtado JC, Coben JL, Butler AH, Riddle EE, Kumar A (2015) Eurasian snow cover variability and links to winter climate in the CMIP5 models. Clim Dyn 45(9):2591-2605. doi:10.1007/ s00382-015-2494-4

Hannachi A, Woollings T, Fraedrich T (2012) The North Atlantic jet stream: preferred positions, paths and transitions. Q J R Meteorol Soc. doi:10.1002/qj.959

Hannachi A, Barnes EA, Woollings T (2013) Behaviour of the winter North Atlantic eddy-driven jet stream in the CMIP3 integrations. Clim Dyn 41(3-4):995-1007. doi:10.1007/s00382-012-1560-4

Hannachi A, Straus DM, Franzke CLE, Corti S, Woollings T (2017) Low frequency nonlinearity and regime behavior in the Northern Hemisphere extra-tropical atmosphere. Rev Geophys. doi:10.10 02/2015RG000509

Held IM, Hou AY (1980) Nonlinear axially symmetric circulations in a nearly inviscid atmosphere. J Atmos Sci 37:515-533

Hoffman HN, Zhou W (2015) Implications of ural blocking for East Asian winter climate in CMIP5 GCMs. Part I: biases in the historical scenario. J Clim 28:203-2216

Hoskins BJ, James IN, White GH (1983) The shape, propagation and mean-flow interaction of large-scale weather systems. J Atmos Sci 40:1595-1612. doi:10.1002/qj.625

Kidston J, Gerber EP (2010) Intermodel variability of the poleward shift of the Austral jet stream in the CMIP3 integrations linked to biases in 20th century climatology. Geophys Res Lett. doi:10. 1029/2010GL042873

Ma J, Xu H, Lin P (2015) Meridional position biases of East Asian subtropical jet stream in CMIP5 models and their relationship with ocean model resolutions. Int J Climatol 35(13):3942-3958. doi:10.1002/joc.4256 
Meinshausen M et al (2011) The RCP greenhouse gas concentrations and their extensions from 1765 to 2300 . Clim Change 109(12):213-241. doi:10.1007/s10584-011-0156-Z

Merz N, Raible CC, Woollings T (2015) North Atlantic eddy-driven jet in interglacial and glacial winter climates. J Clim 28:3977-3997. doi:10.1175/JCLI-D-14-00525.1

Panetta RL, Held IM (1988) Baroclinic eddy fluxes in a one-dimensional model of quasi-geostrophic turbulence. J Atmos Sci 45:3354-3365. doi:10.1175/1520-0469

Scaife AA, Knight JR (2008) Ensemble simulations of the cold European winter of 2005-2006. Q J R Meteorol Soc 134(636):16471659. doi:10.1002/qj.312

Seiler C, Zwiers F (2015) How well do CMIP5 climate models reproduce explosive cyclones in the extratropics of the Northern Hemisphere? Dyn Clim. doi:10.1007/s00382-015-2642-x

Silverman BW (1981) Using kernel density estimates to investigate multimodality. J R Stat Soc 43:97-99

Su F, Duan X, Chen D, Hao Z, Cuo L (2013) Evaluation of the global climate models in the CMIP5 over the Tibetan Plateau. J Clim 26:3187-3208. doi:10.1175/JCLI-D-12-00321
Sura P, Hannachi A (2015) Perspectives of non-Gaussianity in atmospheric synoptic and low-frequency variability. J Clim 28:5091-5114

Wang G, Dommenget D, Frauen C (2014) An evaluation of the CMIP3 and CMIP5 simulations in their skill of simulating the spatial structure of SST variability. Clim Dyn 44:95-114. doi:10.1007/ s00382-014-2154-0

Warner MD, Mass CF, Salathé EP Jr (2015) Changes in winter atmospheric rivers along the North American west coast in CMIP5 climate models. J Hydrometeor 16:118-128. doi:10.1175/ JHM-D-14-0080.1

Woollings T, Blackburn M (2012) The North Atlantic jet stream under climate change and its relation to the NAO and EA patterns. J Clim 25(3):886-902. doi:10.1175/JCLI-D-11-00087.1

Woollings T, Hoskins BJ (2008) Simultaneous Atlantic-Pacific blocking and the northern annular mode. Q J R Meteorol Soc 134(636):1635-1646. doi:10.1002/qj.310

Woollings T, Hannachi A, Hoskins BJ (2010) Variability of the North Atlantic eddy-driven jet stream. Q J R Meteorol Soc 136(649):856-868. doi:10.1002/qj.625 